\title{
BMJ Open Self-administered versus provider- directed sampling in the Anishinaabek Cervical Cancer Screening Study (ACCSS): a qualitative investigation with Canadian First Nations women
}

\author{
Ingeborg Zehbe, ${ }^{1,2}$ Pamela Wakewich, ${ }^{3,4}$ Amy-Dee King, ${ }^{5}$ Kyla Morrisseau, ${ }^{6}$ \\ Candace Tuck ${ }^{7}$
}

To cite: Zehbe I, Wakewich $P$, King A-D, et al. Selfadministered versus providerdirected sampling in the Anishinaabek Cervical Cancer Screening Study (ACCSS): a qualitative investigation with Canadian First Nations women. BMJ Open 2017;7:e017384. doi:10.1136/ bmjopen-2017-017384

- Prepublication history and additional material for this paper are available online. To view please visit the journal (http:// dx.doi.org/10.1136/bmjopen2017-017384).

Received 25 April 2017 Revised 15 June 2017 Accepted 13 July 2017

CrossMark

For numbered affiliations see end of article.

Correspondence to Dr Ingeborg Zehbe; zehbei@tbh.net

\section{ABSTRACT}

Background While (Pap)anicolaou screening has helped to decrease cervical cancer incidence in Canada, First Nations women continue to have a higher burden and mortality relative to mainstream populations. Many First Nations women may feel uncomfortable with the invasiveness of this test, contributing to this statistic. Implemented from 2009 to 2015 in 10 Northwest Ontario First Nations communities, the Anishinaabek Cervical Cancer Screening Study (ACCSS) uniquely addressed this Indigenous health inequity through a mixed methods approach.

Objective Our goal was to offer an alternative test which the women could do themselves: human papillomavirus (HPV) testing based on self-sampling. We investigated whether First Nations women preferred HPV self-sampling over healthcare provider (HCP)-administered Pap screening.

Methods Participatory action researchinformed by the ethical space concept has guided all stages of the ACCSS. We conducted qualitative interviews with $16 \mathrm{HCPs}$ and 8 focus group discussions with 69 female community members followed by a cluster-randomised controlled trial (RCT). Here, we draw on the qualitative field data and an end-of-study community update gathering to disseminate and contextualise research findings. Informant data were evaluated using thematic analysis.

Results We discuss factors influencing participants' strong preference for HPV self-sampling over physicianconducted Pap screening. Key arguments included enhanced accessibility and more personal control, less physical and emotional discomfort and fewer concerns regarding privacy of test results. For future implementation of HPV self-sampling, study participants emphasised the need for more culturally sensitive education addressed to community members of all genders, starting at school, clarifying that HPV causes cervical cancer. Further, HPV infection should be de-stigmatised by accentuating that it affects men and women alike.

Conclusion Here we show that self-sampling in conjunction with community engagement and culturally sensitive education and could be a viable option for underscreened Canadian First Nations women. These informant data echo our previous RCT results.
Strengths and limitations of this study

- The multidisciplinary Anishinaabek Cervical Cancer Screening Study (ACCSS) team uniquely addressed high cervical cancer rates in Canadian First Nations women through a mixed methods initiative.

- Participatory action research enabled the ACCSS team to capture First Nations women's experiences with cervical cancer screening on a personal level using interviews and focus groups.

- Comparative research with other Indigenous communities in Canada and globally is required due to inclusion of only 10 First Nations partner communities in the ACCSS

- Appropriate sexual health education needs to be extended, especially to community men, because all genders can contract human papillomavirus.

\section{INTRODUCTION}

Cervical cancer can be largely prevented through regular screening with Pap(anicolaou) cytology as the current standard of care in most countries with gynaecological cancer prevention programmes. However, cervical cancer incidence remains high for vulnerable populations. This may be an effect of underscreening ${ }^{1}$ associated with healthcare access limitations, ${ }^{23}$ related to travel ${ }^{45}$ and inconsistent service. ${ }^{6}$ In addition, women may not participate because of discomfort or embarrassment regarding the invasive nature of the Pap test, ${ }^{8}$ language barriers ${ }^{9}$ or cultural sensitivity issues. ${ }^{1011}$ There is increasing evidence that women see self-sampling for human papillomavirus (HPV) testing as an option for overcoming these inadequacies ${ }^{12}$ which may lead to significant improvements in screening rates among underscreened women. ${ }^{13-18}$

Self-sampling is a feasible and cost-effective alternative for enhancing access to screening 
in underserved rural areas ${ }^{19-23}$ and is perceived as being easy to use,${ }^{24-26}$ given sufficient information is provided to alleviate women's concerns about correctly inserting the swab and collecting a sample. ${ }^{412728}$ As the specificity and accuracy of HPV self-testing is comparable to physician-administered HPV tests, ${ }^{29}$ self-sampling has been approved as an option for underscreened or never-screened women in the Netherlands since $2001^{30}$ and is slated for approval in Australia by $2017 .{ }^{31}{ }^{32}$ Some concern has been raised about the ability of this method to serve ethnic, religious, educational and age groups that historically have been under-represented in conventional screening programme. ${ }^{33}$ In contrast, initial studies conducted with Indigenous peoples of Canada and the USA, that is, in Inuit $^{3435}$ and First Nations women in Canada ${ }^{36}$ as well as Hopi women in the USA, ${ }^{37}$ suggest that self-sampling is preferable to provider-directed Pap screening.

In Canada, Australia, New Zealand and the USA, Indigenous women have disproportionately high incidence and mortality rates from cervical cancer. In the Canadian province of Ontario, First Nations women are twice as likely to be diagnosed with cervical cancer and die from it. ${ }^{38}$ To address this Indigenous health inequity ${ }^{39}$ we conducted the mixed methods Anishinaabek Cervical Cancer Screening Study (ACCSS) which consisted of qualitative and quantitative components. ${ }^{40}$ The ACCSS used a participatory action research (PAR) approach informed by Ermine's ethical space concept. ${ }^{41}$ Our aim was to assess whether offering alternative self-sampling could lead to increased screening participation. Here, we present our qualitative results. We draw on testimonies obtained through interviews and focus group discussions as well as a knowledge transfer gathering at the end of study. These findings endorse our quantitative data from the ACCSS' randomised controlled trial (RCT) where women were twice as likely to get screened if offered self-sampling rather than Pap testing. ${ }^{42}$

\section{METHODOLOGY}

\section{Research context}

The principal investigator (IZ), a non-Indigenous, female cancer biologist (PhD) with a background in cultural anthropology and an interest in Indigenous health disparities to address cervical cancer rates in Ontario, Canada, conducted a pilot study (April to December 2009) with one First Nations community in the Thunder Bay region. The majority of participants (87\%) preferred HPV self-sampling over Pap testing. ${ }^{36}$ IZ was then invited to the Northern Superior All Chiefs Meeting in October 2010 to expand the screening study to other regional communities. ${ }^{43}$ Research agreements were formally ratified (winter 2010 and spring 2011) followed by 'Meet and Greet' information sessions conducted in the 10 participating communities (spring 2011) to discuss the research. ${ }^{43}$ These Robinson Superior Treaty communities which are part of the Anishinaabek
Nation lie within a $500 \mathrm{~km}$ radius of the city of Thunder Bay, the region's health and social service centre. They have on reserve populations ranging from 70 to 832 members. ${ }^{40} 42$

\section{Research approach}

PAR informed by Ermine's ethical space concept $(2007)^{41}$ to bridge diverging cultural worldviews has guided the ACCSS design, conduct, data analysis and results' dissemination with continuous communication between partner communities and the multidisciplinary academic team (medical sciences, eg, cancer biology, epidemiology and virology as well as social sciences, eg, sociology, medical anthropology and women's studies) (www.accssfn.com). ${ }^{43}$ In addition to field trips to the communities for data collection, regular teleconferences have enabled active and ongoing participation of members from more geographically distant communities and helped to link communities and project staff to one another. A publication steering committee (PSC) consisting of one representative from each participating community-that is, the senior health manager, was established to review prospective reports and publications with up to three ad hoc PSC members or delegates recruited as coauthors for each submitted peer-reviewed publication. Each publication was also sent to the communities' political leadership for approval.

\section{Study design}

To add rigour to our investigation and to understand the dynamics of cervical cancer screening attitudes, a mixed methods study design ${ }^{44}$ was used for the larger study conducted between August 2011 and October 2015. ${ }^{40}$ In the qualitative component, with parts reported here, we obtained information in two ways: (1) through in-depth interviews with 16 indigenous community healthcare providers (HCPs) with a broad range of roles (from all 10 communities; summer 2011) and (2) through 8 focus groups with a total of 69 community women (from 8 communities; spring and summer 2012). Thereafter, sample saturation was reached. In the quantitative component, an RCT was conducted with the same 10 partner communities with 834 eligible women to assess uptake of self-administered HPV sampling versus Pap screening (spring 2013 to spring 2014). ${ }^{42}$ Together with community-based research assistants (CBRAs) - recruited from women living in the partner communities-IZ conducted educational sessions to explain the study during the RCT. CBRAs enrolled participants and provided self-sampling kits or organised Pap-screening. Participants could choose the HCP who would report results back to them. All women with positive test results were immediately referred to the provincial standard of care for treatment and/ or follow-up. Data management and analysis occurred between summer 2014 to summer $2015 .^{42}$ 


\section{Sampling strategy}

\section{Interviews and focus groups}

The senior health manager in each community recruited 1-2 HCP informants to participate in individual interviews through purposive sampling. The HCPs approached were those most familiar with community reproductive care and sexual health service provision. ${ }^{40}$ Their ages ranged from mid-20s to late 60s. Occupations included physicians, nurses, nurse-practitioners, social workers and community health representatives. The length of time they had spent working in their community varied between 6 months and 15 years. Fifteen HCPs were female and one was male. Of these, 10 women self-identified as First Nations. Their intersectional perspectives ${ }^{45}$ as HCPs, as First Nations peoples and as community residents enriched the interviews and allowed a better understanding of the complex issues impacting the cervical cancer screening environment. Ten interviews were conducted in-person and six via videoconference.

At the recommendation of our community partners, we did focus groups (resembling talking circles) rather than individual interviews with community women to enhance their comfort participating in research on a sensitive topic. The senior community health managers recruited participants of mixed ages, including teens, middle-aged women and elders (up to $\sim 70$ years of age). Women who self-identified as First Nations female residents in any of the participating communities with a minimum age of 18 and without formal health education beyond secondary school (for a diversity of perspectives and to complement the voices of HCPs) were eligible. A meal was shared during the sessions (mostly held at community centres) and, as is common for research with indigenous communities in Canada, participants were offered a monetary incentive (\$C75), to show respect for their time and contributions to the project. IZ conducted the interviews and focus groups with a medical anthropologist (Dr Marion Maar, Acknowledgements) skilled in leading individual and group interviews. HCP interviews and focus groups followed an open-ended, semistructured grounded theory approach, enabling new ideas and questions to arise from the participants, enriching the researchers' thinking and concepts. For comparative purposes, key topics were probed in each focus group. Supplementary questions and discussion were guided by participant response and questions to the facilitators. Sessions usually began with a broad stimulus question on the experiences with cancer in their community, followed by community concerns about cancer, knowledge and awareness of cervical cancer screening, availability and experiences with PAP screening, barriers and facilitators to screening, a description of HPV self-sampling and interest in a self-sampling trial (online supplementary material). Interviews lasted 40-90 min and focus groups 80-120 min, with participants' permission to be audiotaped for later analysis. A note taker was present during focus group sessions. No individual or focus group participant in the 10 communities, reported here, withdrew.

\section{Community update gathering}

Our qualitative data set also included reflections on self-sampling versus Pap screening as reported and discussed at the 2-day ACCSS community update gathering (CUG) held in a Thunder Bay hotel at the end of study in October 2015. Altogether 35 persons (32 females and 3 males) were in attendance: partner community representatives (13 HCPs by invitation of 1-2 representatives per community decided by each community's senior health manager-some of whom had participated in the interviews; 4 CBRAs who helped with recruitment during the $\mathrm{RCT}^{42}$-none had participated in the interviews or focus groups; 1 elder; $n=18$ ), 6 ACCSS researchers, 1 commissioned Indigenous organiser and facilitator, 1 Indigenous academic researcher outside the ACCSS team, 5 delegates from Cancer Care Ontario and 1 from the Society of Gynaecologists and Obstetricians of Canada, 1 Anishinaabek male artist, who had designed the ACCSS study logos (www.accssfn.com), 2 local male undergraduate students volunteering for the ACCSS and 3 female note takers. The CUG used multiple discussion formats modelled on talking circles to gather participant perspectives on the successes and challenges of the ACCSS. We began with an opening talking circle which allowed participants to offer their spontaneous reflections on the ACCSS, followed by a World Café structured group discussion format ${ }^{46}$ in which participants were assigned to one of three groups and moved through three facilitated discussion stations each addressing an assigned question: (1) what worked and what could have been done better, (2) best approaches to deliver culturally sensitive cancer prevention education and (3) future directions based on project successes. After the World Café session, a summative talking circle ended the gathering.

\section{Data analysis}

Multiple levels of analysis were employed with the qualitative data. Deidentified transcripts from interviews, focus groups and the CUG were manually coded by IZ and PW using open coding ${ }^{47}$ to identify basic themes which were grouped into global themes through review and discussion. ${ }^{48}$ A commissioned rural health senior researcher (Dr Mary Ellen Hill) uploaded the deidentified transcripts into Nvivo 9 (QSR International) and assisted us to more comprehensively identify the multiple locations and contexts in which the basic and global themes appeared in the transcripts. We shared our findings and obtained feedback from the community informants via an educational workshop held in Thunder Bay in October 2012 (interviewees), ${ }^{49}$ community visits from December 2013 to March 2014 (focus group members) and community visits in December 2015 (CUG participants and community leadership). No diverging evidence or inconsistent data were identified. Independent review of the transcripts, code book and discussions by IZ and $\mathrm{PW}^{44}$ led to the identification of 15 basic and 5 global themes (figure 1). 


\section{BASIC THEMES}

No regular screening services

Lack of provider flexibility

Transportation and child care issues

No efficient follow up

Privacy concerns

\section{GLOBAL THEMES}

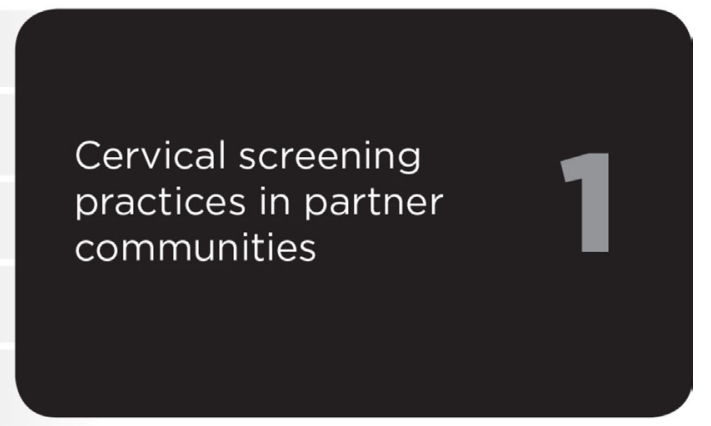

\section{Physical comfort level}

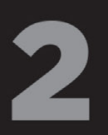

Self-sampling is less painful

Psychological

comfort level
Convenience factor self-sampling

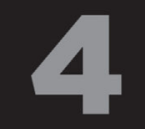

Need explain self-sampling

Women being blamed for STIs

Contribution to stereotype

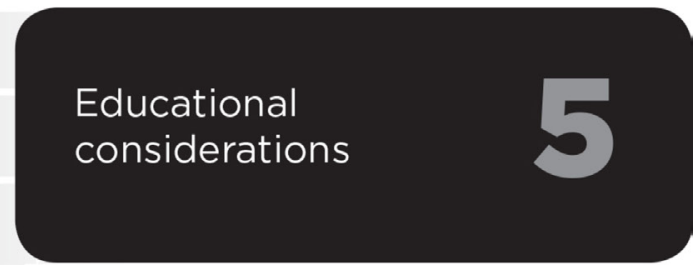

Figure 1 Basic and global themes deduced from interviews and focus groups. STI, sexually transmitted infection.

In the quotes cited below, I stands for interview, FG for focus group, and regarding the CUG, OC for opening (talking) circle, WC1-3 for respective World Café (discussion station) or SC for summative (talking) circle. Only quotes from community representatives were reported. Due to confidentiality reasons, these were not individualised.

\section{RESULTS}

Cervical screening practices in partner communities No regular screening services

Pap testing is the standard of care for cervical cancer screening in Ontario. Screening is opportunistic without a formal recall system and participation rates have not been assessed. As community visits from locum physicians or nurse practitioners are usually infrequent and community nurses are not certified to do Pap testing, many women living in small rural First Nations communities need to travel to nearby towns to attend Pap clinics in conjunction with seeking other services. The time required to travel and keep appointments is a disruption to their everyday lives and a significant barrier to accessing care. As a woman emphasised: 'Most of us do not have doctors here ... you have to drive up to [nearby town]' (FG1).

Lack of provider flexibility

Those who can access care through nearby small-town health centres and family health teams, located 40-60 km 
away, reported that clinics often only offered Pap tests on certain days of the week. Frequently, physicians were called away to emergencies, so appointments were cancelled and rescheduled. Recounting her experience, a woman said: 'I don't know how many times they've cancelled Pap tests and [when I asked] "okay well can I get it on Friday? .... [heard back] "No, we don't do them on Friday"' (FG2).

\section{Transportation and child care issues}

Women who elected to access care through a family practitioner, walk-in clinic or gynaecologist in Thunder Bay, located $60-200 \mathrm{~km}$ away from their communities, often found that it was difficult to arrange transportation. Space was limited in the community medical van, which travelled to the city only certain days of the week and, if overnight stay was required, accommodations had to be found: 'If the van was full, [you would] have to get a ride ... some of us don't have cars, you know' (FG7). Women with children and work commitments also had difficulty arranging childcare and time off work to keep their appointments. As a HCP commented: 'It certainly does pose challenges with regards to babysitting care and the mother being away for an entire day' (I16).

\section{No efficient follow-up}

Some women noted that they had to 'wait and wait' to hear back from their providers and, in many instances, did not hear back about their results until they visited the health centre for another reason. As one focus group participant noted: 'It's crazy here, how long you have to wait for anything and half the time, you don't even get a call ... you go to your next doctor's appointment for something else and [have to ask] ... by the way, how about my Pap two months ago?' (FG2).

\section{Privacy concerns}

Those who were recalled for results spoke of privacy concerns at small community health centres where staff 'phoning people, telling them, 'we've got your results ... you need to make another appointment' (FG2) was upsetting. As one woman said: 'I don't want nobody else to know' (FG2). Due to stigma, they need reassurance that results 'did not get out into the community' (I16).

Conversely, there was a view that self-sampling was 'a lot more private, at home, if you do it by yourself' (FG4). Picking up a self-test, doing the test at home, mailing it away and getting results by mail offered much more privacy and confidentiality than the alternative of having to make appointments at the health centre. One woman said: 'Women would prefer to be discreet, do it themselves and get their own results and not have their results shared with others' (FG1).

\section{Physical comfort level}

\section{Paps hurt}

Although some women who were used to getting Paps felt that 'it's kind of a routine after a while ... they open you up and they swab and then you're done' (FG2) or 'the Pap is uncomfortable but it has to be done' (FG4), other women continued to experience anxiety, even after having Paps on a regular basis: 'it doesn't get any easier, like the first time and then the next year, it didn't get any easier for me' (FG2). One woman who had gone for one and never had another Pap said: 'I didn't like the way it felt, that's why I didn't want to go back there' (FG9). Another said that the 'pain' associated with the test had stopped a lot of women: 'They don't want their Paps [be] cause it hurt' (FG1). The test also could be exceptionally painful if providers were 'in a rush' or 'rough' and did the procedure 'real quick' (FG8). From the point of view of an HCP: 'Some women, when they come to the appointment, they decide they don't want to get a Pap, because it's uncomfortable, they're just afraid' (I8).

\section{Self-sampling is less painful}

Self-sampling was seen as advantageous and may increase screening participation because the procedure itself was thought of as being 'less invasive' and 'less painful' than having a Pap test (I6). The prospect of testing using a 'swab' yourself was much more comfortable than having to submit to an HCP examination with "metal or plastic instruments' (FG1). As a woman said: 'Women wouldn't be so agitated and nervous about having the [self-] test' (FG4).

HCPs also supported the idea of self-sampling, seeing it as less invasive, as this quote suggests: 'It's a lot less clinical ... stripping down and allowing someone else to do the scraping of the cervix, the whole uncomfortable procedure of going through a Pap opposed to doing it privately in the bathroom on your own is a huge difference.' '...I think the prevalence [participation] rate would go up' (I1). The Pap procedure on the other hand was viewed as being 'such an invasive part of a check-up from the doctor [and] women don't like to get that done' (FG9).

Similar opinions were also expressed at the CUG:

[Self-sampling] is less invasive. A lot of them experience ... not good memories growing up and what not; so it was a little harder to get the Elders involved, but once we did, it kind of made the women more comfortable and we got a lot of results through the community there. [I said] if you wanted to come by my house ... I have the kits, I got a washroom and whatever ... It was always on their terms because I felt like giving it to them on their terms was better ... It was really, really good for our community because it's like, uh, the snowball effect ... And now I have people asking me like when can I do this [self-sampling] ... but a lot of the women shied away from the Pap test. (SC)

\section{Psychological comfort level}

Male provider or not

Several women noted that they were embarrassed at having Paps performed by a male physician and would 'feel more comfortable [with a female physician or nurse 
practitioner] because maybe she's going through the same thing that you're going through' (FG2). Others felt that they would be 'embarrassed anyway, no matter who did it' (FG2). Likewise, a young woman said: 'I only got a Pap test once and I got it from a woman ... and she was trying to make me feel comfortable, but it's still really awkward' (FG4).

\section{Age factor}

There was a view, as an HCP stated that: 'The older women, and then the really young newly sexually active young girls are a little reluctant to get their Paps. We have a long time with that' (I1). Young women often delayed making appointments for Pap tests and birth control for fear that their HCPs, and by extension, their families, would know that they were sexually active. This relates to sexual stigma as one woman said: 'I was sexually active for a while before I even went for my first one ... I was nervous about it because ... all the nurses and the doctors know each other' (FG2). Older women with histories of sexual abuse or residential school experiences ${ }^{50}$ were reluctant to go to HCPs generally as they were fearful of being 'touched' (I7). In the words of a focus group participant: 'If you're a culture that has been impacted by residential school, colonization ... it's going to be ... ten times harder for us to go to a male doctor' (FG1). An HCP said: 'The reason why they don't go get screened [is] maybe because their suffering from post-traumatic stress and [going for a Pap test] maybe it triggers [the stress] in people' (I4).

At the CUG, respondents also commented on the interest in self-sampling among young women in their communities, including those under 25 who were not yet eligible to participate. They noted that this was a population to whom education and screening should be extended to capitalise on continuing screening for the future:

What I want to add, is to have that sustainability, I think we need to address the younger ones to get them ready for 26 and over, you know. Like some communities I work with, I can see that it's staying around because they still ask me, can we do the selfsample? Sure, they're all about the self-sampling too because I mean it's actually based on stuff that [they are comfortable with]. (WC3)

\section{High comfort with self-sampling}

The consensus was that self-sampling for HPV testing would increase comfort and reduce embarrassment. Women commented that 'doing it yourself would be better' than having an HCP (FG2). Others emphasised they 'would feel more comfortable with that [self-test] than a male doctor' (FG5). Doing one's own test was also seen as easier for people who reported being frightened or 'shy' of doctors or nurses who visited the communities (FG8). Self-testing would also address the 'trust issues' that discouraged women from seeking care from non-indigenous HCPs (FG5).

\section{Convenience factor self-sampling}

More privacy

Having the test available at home might encourage more women to do the test: 'I think more people would monitor it that way and test it themselves, like "well maybe not today, but ... eventually I'm going to try it' (FG2). From an HCP perspective, giving women the option of self-testing in a clinical setting or giving them the option of taking it home might make women 'feel more empowered' and contribute to a better relationship with HCPs (I8), or first-time users could get help from their provider: 'An option, they can either do it themselves, or you can offer to do it for them' (I4).

\section{No appointment needed for self-sampling}

Summing up her views regarding self-sampling, a focus group participant said: 'It is more comfortable to do it at home ... it's simple'. The test would also eliminate the necessity of scheduling out-of-town appointments and travelling to a small town or city to access care (FG6). Another said: 'I think the self-test is beneficial for them all because sometimes people don't have time for appointments to take off work, it [the Pap] is kind of an inconvenience'. Self-testing was also viewed as 'more convenient' because women could keep the kits at home (FG4).

Overall, the ease of accessing self-sampling seemed appealing to younger women who were busy with work and childcare and 'would go for it'; less so for some older woman who had fewer constraints on their time and 'were used to getting Paps' (FG4). Regarding the convenience of self-testing, an HCP said: 'Even hearing [about self-testing], people are just, What? Oh, I'd do that, for sure, instead of me going to the doctor' (I3). Another provider said: 'Doing a self-test doesn't take very long ... it's something that can be dealt with, done, gone' (I10).

The above voices were echoed during the CUG reinforcing that self-sampling is comfortable and enhances their control of the screening process as the following quote illustrates:

I really strongly believe that ... because I was the one that was doing it [self-sampling], I was the one that was in control ... and this way it gave me the ability to do it myself and I got all the results, they were fine; ... it was also self-empowering, great, I like that. (OC)

\section{Educational implications}

Need to explain self-sampling

While the informants generally reacted positively towards 'a new screening tool', some of the HCPs indicated reservations for immediate use of self-testing. HCPs felt that education around self-testing might better be done in the context of a well woman healthcare visit, as 'part of a physical, that might get best [results]' (I8). They were concerned that, without education, women would not necessarily understand that they would still need to go to their HCP for other reproductive healthcare: 'They 
would, they'd probably think, well, I've had that done, so I don't need this done' (I8).

Further emphasising the need for education, one HCP interviewee said: 'If you hand me a kit, I won't touch it. Because I wouldn't know what to do, what if I did it wrong, or whatever, right, so? And I think a lot of people would be that way' (I3). Another expressed a similar concern: 'If you just give a test kit to them at home, the majority of them are just going to throw them out'.

\section{Women being blamed for sexually transmitted infections}

Reluctance to self-test for HPV was also related to fear that women would be blamed for having a sexually transmitted infection (STI): 'HPV, like, whoa, I don't have that, like, I don't even want to know if I have that' (I8). Women were distressed about testing for STIs, 'because it's a relationship thing' that implied that someone had 'cheated' (I1). Indeed, a focus group participant wondered: '.... do they [the men] not need to know some of this stuff too?' (FG1). '... I know only women get cervical cancer but ... they've helping it along in the same sense where they've passing it back and forth' (FG1).

\section{Contribution to stereotype}

Focus group participants were concerned that any publication of information about HPV rates on reserve could have negative effects, contributing to the stereotype that 'all native people have HPV' (FG6). As one HCP summarised: 'A lot more education has to be done about HPV and cervical cancer together' to alleviate these concerns (I8).

\section{DISCUSSION}

The ACCSS provides insights into an important Indigenous health inequity as it uniquely addresses high cervical cancer rates in Canadian First Nations using a mixed methods qualitative and quantitative approach. Face-toface testimonies by our informants, especially those from the focus groups, demonstrate that self-sampling is the preferred method over Pap testing in the ACCSS partner communities-supporting our previous quantitative RCT data. ${ }^{42}$ At the 2-day CUG which was held to discuss the successes and challenges of the ACCSS, the community representatives confirmed a strong preference among the women in their communities for HPV self-sampling. They concluded that offering self-sampling on a continuing basis would maximise women's ability to screen at times and in places which would make them most comfortable and enhance their control of the screening process. A limitation of our study is that we included only 10 First Nations communities from Northwest Ontario in Canada. However, other Indigenous women worldwide share similar colonial experiences and socioeconomic disadvantages. While our findings require validation, they may be helpful for initiating comparative studies in Canada and elsewhere.
Worldwide, women not participating in Pap testing tend to accept HPV self-sampling instead ${ }^{51-55}$ - a fact largely resonating with the voices from our informants: the self-test has been reported to overcome issues with transportation, childcare and the inconvenience of having to go to a clinic for screening ${ }^{56}{ }^{57}$; it increases women's autonomy and addresses social barriers in rural communities ${ }^{20} 21$; it is viewed as more private and

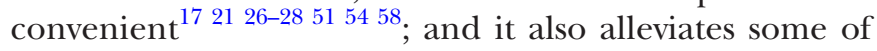
the personal stress, for example, physical and emotional discomfort of having Paps. ${ }^{27} 2853$ Those who prefer Paps have more confidence in clinicians because they are concerned about doing the self-test accurately. ${ }^{28}{ }^{28}$ This and the concern that women may not show up for other reproductive healthcare when doing self-sampling were raised by a few HCP informants which, as also suggested by them, could be addressed through appropriate education prior to testing.

To make women aware of the benefits of cervical screening through culturally sensitive education was a recurring theme throughout the process of the ACCSS and has not been testified as such in other studies. Our informants recommended educational strategies adapted to their communities' needs, various age groups and both sexes as previously reported by us. ${ }^{49}{ }^{59}$ To make HPV self-sampling successful, appropriate information, such as is provided along with the faecal blood self-test for colon cancer, is necessary, as also pointed out in other research. ${ }^{24}{ }^{60}$ To de-stigmatise sexually transmitted HPV, men must be made aware that both they and women can be carriers of HPV infecting each other. The current notion, suggested by our informants, is that men in their communities are unaware of this fact. This may contribute negatively to younger women attending cervical screening. This limitation in information still needs to be adequately addressed as cervical screening generally is scheduled around sexual activity (often without HCPs mentioning the cause) and self-sampling is valid for HPV testing only.

In conclusion, most ACCSS informants communicated a clear preference for HPV self-sampling over Pap screening. Offering this alternate cervical screening tool would free up HCP time and eliminate several structural barriers. HPV testing is a superior proxy over Pap cytology to detect cervical lesions early enough for treatment and has already become the primary cervical cancer check in some countries. ${ }^{30-32}$ The ACCSS results should be helpful to stakeholders and decision makers who are in charge to design future screening programme including follow-up of abnormal results and access to quality care. Special requirements for underserved populations are required to overcome current barriers discussed here and previously. ${ }^{461}$ The ACCSS team regularly shares results with its Anishinaabek partner communities, the public, decision makers and the scientific community. The end of study CUG was an example of such knowledge dissemination. Overall, and most likely due to the PAR approach, our experience with the Anishinaabek partner communities has been truly positive with a fruitful and candid 
exchange of ideas between both groups. This became increasingly clear during the CUG with a reflection on lessons learnt and strong community-guided suggestions for future education and research (Wakewich and Zehbe, in preparation).

\section{Author affiliations}

${ }^{1}$ Department of Biology, Lakehead University, Thunder Bay, Canada

${ }^{2}$ Probe Development and Biomarker Exploration, Thunder Bay Regional Health

Research Institute, Thunder Bay, Canada

${ }^{3}$ The Centre for Rural and Northern Health Research, Lakehead University, Thunder Bay, Canada

${ }^{4}$ Department of Sociology and Women's Studies, Lakehead University, Thunder Bay, Canada

${ }^{5}$ Band Office, Biinjitiwaabik Zaaging Anishinaabek First Nation, Thunder Bay, Canada ${ }^{6}$ Band Office, Animbiigo Zaagi' igan Anishinaabek First Nation, Thunder Bay, Canada ${ }^{7}$ Band Office, Red Rock Indian Band, Thunder Bay, Canada

Acknowledgements Thanks are conveyed to all HCP interviewees and Acknowledgements focus group participants for their insight and for sharing their knowledge with the ACCSS research team as well as to the community representatives (senior health managers), the chiefs and council members of the Robinson Superior First Nations communities for continuous support of our work. The authors also acknowledge the contribution to the data collection by Marion Maar (Northern Ontario School of Medicine). Finally, they thank Mary Ellen Hill for assisting with the NVivo analysis and Melissa Togtema for critical reading and helpful comments on the manuscript.

Contributors IZ conceived and designed the study, completed all field work, including prior community engagement and formal community research agreements and led the writing of the manuscript. PW and IZ analysed the data. PW drafted the Materials and methods section. A-DK, KM and CT contributed to the field work in their own communities and critically revised the manuscript keeping in mind cultural safety. All authors have read and approved the final version of the manuscript and agreed to act as guarantors of the work therein.

Funding This work was funded by the Canadian Institutes of Health Research(CIHR) with IZ being the nominated principal investigator (CIHR \# MOP-119344).

Competing interests None declared.

Patient consent Obtained.

Ethics approval The ACCSS was approved by the principal investigator's host institution (Lakehead University Research Ethics Board \#038 11-12/ROMEO $\# 1462079$ and 12-13/ROME0 \#1463139). As requested for ethics approval, the ACCSS design is based on the Ownership, Control, Access and Possession (OCAP) Guidelines recommended by the First Nations Information Governance Centre (FNIGC, 2016; http://fnigc.ca/ocap.html) and respects the terms of the tri-council policy statement on research involving the first nations, inuit and metis people of Canada (CIHR, NSERC, SSHRC 2014; http://www.pre.ethics.gc.ca/eng/policypolitique/initiatives/tcps2-eptc2/chapter9-chapit).

Provenance and peer review Not commissioned; externally peer reviewed.

Data sharing statement № additional data are available.

Open Access This is an Open Access article distributed in accordance with the Creative Commons Attribution Non Commercial (CC BY-NC 4.0) license, which permits others to distribute, remix, adapt, build upon this work non-commercially, and license their derivative works on different terms, provided the original work is properly cited and the use is non-commercial. See: http://creativecommons.org/ licenses/by-nc/4.0/

(C) Article author(s) (or their employer(s) unless otherwise stated in the text of the article) 2017. All rights reserved. No commercial use is permitted unless otherwise expressly granted.

\section{REFERENCES}

1. Moore SP, Antoni S, Colquhoun A, et al. Cancer incidence in indigenous people in Australia, New Zealand, Canada, and the USA: a comparative population-based study. Lancet Oncol 2015;16:1483-92.
2. Clement KM, Mansour D. Invasive cancer of the cervix: does the UK National Health Service screening programme fail due to patients non-attendance? Eur J Gynaecol Oncol 2013;34:28-30.

3. Subramaniam A, Fauci JM, Schneider KE, et al. Invasive cervical cancer and screening: what are the rates of unscreened and underscreened women in the modern era? J Low Genit Tract Dis 2011;15:110-3.

4. Maar M, Burchell A, Little J, et al. A qualitative study of provider perspectives of structural barriers to cervical cancer screening among first nations women. Womens Health Issues 2013;23:e319-e325.

5. Studts CR, Tarasenko YN, Schoenberg NE. Barriers to cervical cancer screening among middle-aged and older rural Appalachian women. J Community Health 2013;38:500-12.

6. Racey CS, Gesink DC. Barriers and facilitators to cervical cancer screening among women in rural Ontario, Canada: The role of selfcollected HPV testing. J Rural Health 2016;32:136-45.

7. Schoenberg NE, Hopenhayn C, Christian A, et al. An in-depth and updated perspective on determinants of cervical cancer screening among central Appalachian women. Women Health 2005;42:89-105.

8. Yu CK, Rymer J. Women's attitudes to and awareness of smear testing and cervical cancer. Br J Fam Plann 1998;23:127-33.

9. Karwalajtys TL, Redwood-Campbell LJ, Fowler NC, et al. Conducting qualitative research on cervical cancer screening among diverse groups of immigrant women: research reflections: challenges and solutions. Can Fam Physician 2010;56:e130-5.

10. Lovell S, Kearns RA, Friesen W. Sociocultural barriers to cervical screening in South Auckland, New Zealand. Soc Sci Med 2007;65:138-50.

11. Maxwell AE, Young S, Rabelo Vega $R$, et al. Building capacity to address women's health issues in the mixtec and zapotec Community. Womens Health Issues 2015;25:403-9.

12. Rosenbaum AJ, Gage JC, Alfaro KM, et al. Acceptability of self-collected versus provider-collected sampling for HPV DNA testing among women in rural El Salvador. Int $J$ Gynaecol Obstet 2014;126:156-60.

13. Arrossi S, Thouyaret L, Herrero R, et al. Effect of self-collection of HPV DNA offered by community health workers at home visits on uptake of screening for cervical cancer (the EMA study): a population-based cluster-randomised trial. Lancet Glob Health 2015;3:e85-e94.

14. Camilloni L, Ferroni E, Cendales BJ, et al.Methods to increase participation in organised screening programs: a systematic review. BMC Public Health 2013;13:464.

15. Mullins R, Scalzo K, Sultana F. Self-sampling for cervical screening: could it overcome some of the barriers to the Pap test? J Med Screen 2014;21:201-6.

16. Speck NM, Pinheiro JS, Pereira ER, et al. Cervical cancer screening in young and elderly women of the xingu indigenous park: evaluation of the recommended screening age group in Brazil. Einstein 2015;13:52-7.

17. Sultana F, English DR, Simpson JA, et al. Home-based HPV selfsampling improves participation by never-screened and underscreened women: results from a large randomized trial (iPap) in Australia. Int J Cancer 2016;139:281-90.

18. Nelson EJ, Maynard BR, Loux T, et al. The acceptability of selfsampled screening for HPV DNA: a systematic review and metaanalysis. Sex Transm Infect 2017;93:56-61.

19. Castle PE, Rausa A, Walls T, et al. Comparative community outreach to increase cervical cancer screening in the Mississippi Delta. Prev Med 2011;52:452-5.

20. Duke P, Godwin M, Ratnam S, et al. Effect of vaginal self-sampling on cervical cancer screening rates: a community-based study in Newfoundland. BMC Womens Health 2015;15:47.

21. Racey CS, Withrow DR, Gesink D. Self-collected HPV testing improves participation in cervical cancer screening: a systematic review and meta-analysis. Can J Public Health 2013;104:e159-66.

22. Vanderpool RC, Jones MG, Stradtman LR, et al. Self-collecting a cervico-vaginal specimen for cervical cancer screening: an exploratory study of acceptability among medically underserved women in rural Appalachia. Gynecol Oncol 2014;132 Suppl 1(S1):S21-S25.

23. Racey CS, Gesink DC, Burchell AN, et al. Randomized intervention of self-collected sampling for human papillomavirus testing in underscreened rural women: uptake of screening and acceptability. $J$ Womens Health 2016;25:489-97.

24. Bansil P, Wittet S, Lim JL, et al. Acceptability of self-collection sampling for HPV-DNA testing in low-resource settings: a mixed methods approach. BMC Public Health 2014;14:596.

25. Scarinci IC, Litton AG, Garcés-Palacio IC, et al. Acceptability and usability of self-collected sampling for HPV testing among African- 
American women living in the Mississippi Delta. Womens Health Issues 2013;23:e123-e130.

26. Virtanen A, Nieminen P, Niironen M, et al. Self-sampling experiences among non-attendees to cervical screening. Gynecol Oncol 2014;135:487-94.

27. Anhang R, Nelson JA, Telerant R, et al. Acceptability of self-collection of specimens for HPV DNA testing in an urban population. $J$ Womens Health 2005;14:721-8.

28. Huynh J, Howard M, Lytwyn A. Self-collection for vaginal human papillomavirus testing: systematic review of studies asking women their perceptions. J Low Genit Tract Dis 2010;14:356-62.

29. Arbyn M, Verdoodt F, Snijders PJ, et al. Accuracy of human papillomavirus testing on self-collected versus clinician-collected samples: a meta-analysis. Lancet Oncol 2014;15:172-83.

30. Verdoodt F, Jentschke M, Hillemanns $P$, et al. Reaching women who do not participate in the regular cervical cancer screening programme by offering self-sampling kits: a systematic review and meta-analysis of randomised trials. Eur J Cancer 2015;51:2375-85.

31. Australian government, department of health. Cancer screening: future changes to cervical cancer screening. $2015 \mathrm{http} / / / \mathrm{www}$. cancerscreening.gov.au/ (accessed 10 May 2015).

32. Smith M, Lew JB, Simms K, et al. Impact of HPV sample selfcollection for underscreened women in the renewed cervical screening program. Med J Aust 2016;204:194.

33. Howard M, Lytwyn A, Lohfeld L, et al. Barriers to acceptance of selfsampling for human papillomavirus across ethnolinguistic groups of women. Can J Public Health 2009;100:365-9.

34. Cerigo H, Macdonald ME, Franco EL, et al. HPV detection by self-sampling in Nunavik, Quebec: Inuit women's sampling method preferences. J Abor Health 2012;8:29-39.

35. Cerigo H, Coutlée F, Franco EL, et al. Factors associated with cervical cancer screening uptake among inuit women in Nunavik, Quebec, Canada. BMC Public Health 2013;13:438.

36. Zehbe I, Moeller H, Severini A, et al. Feasibility of self-sampling and human papillomavirus testing for cervical cancer screening in first nation women from Northwest Ontario, Canada: a pilot study. BMJ Open 2011;1:e000030.

37. Winner RL, Gonzales AA, Noonan CJ, et al. Collaborative to Improve Native Cancer Outcomes (CINCO). Assessing acceptability of selfsampling kits, prevalence, and risk factors for human papillomavirus infection in American Indian women. J Community Health 2016;41:1049-61.

38. Marrett LD, Chaudhry M. Cancer incidence and mortality in Ontario first nations, 1968-1991 (Canada). Cancer Causes Control 2003;14:259-68.

39. Smylie J. The Health of aboriginal peoples. Social determinants of health. 2nd Edition. Toronto, Ontario, Canada: Canadian Scholars Press, 2009:280-301.

40. Wood B, Burchell AN, Escott N, et al. Using community engagement to inform and implement a community-randomized controlled trial in the anishinaabek cervical cancer screening study. Front Oncol 2014;4:27.

41. Ermine W. The ethical space of engagement. Indigenous Law J 2007;6:193-202.

42. Zehbe I, Jackson R, Wood B, et al. Community-randomised controlled trial embedded in the anishinaabek cervical cancer screening study: human papillomavirus self-sampling versus papanicolaou cytology. BMJ Open 2016;6:e011754.

43. Zehbe I, Maar M, Berst KSM, et al. Ethical space for a sensitive research topic: engaging First Nations women in the development of culturally safe human papillomavirus screening. $J$ Aboriginal Health 2012;8:41-50.
44. Creswell JW. Qualitative Enquiry and Research Design. $3^{\text {rd }}$ Edition. Thousand Oaks, California, U.S.A: Sage Publishing, 20122012.

45. Hankivsky O, Grace D, Hunting G, et al. An intersectionality-based policy analysis framework: critical reflections on a methodology for advancing equity. Int $J$ Equity Health 2014;13:119.

46. Brown J, Isaacs D. The world cafe book: shaping our futures through conversations that matter. With the world cafe community of practice. Oakland, California, U.S.A: Berrett-Koehler publishing, 2005.

47. van den Hoonaard DK. Qualitative research in action: a canadian primer. $2^{\text {nd }}$ Edition: Don Mills, Ontario, Canada Oxford University Press Canada, 2015.

48. Attride-Stirling J. Thematic networks: an analytic tool for qualitative research. Qualitative Research 2001;1:385-405.

49. Zehbe I, Wood B, Wakewich P, et al. Teaching tools to engage anishinaabek first nations women in cervical cancer screening: report of an educational workshop. Health Educ J 2016;75:331-42.

50. The truth and reconciliation commission of Canada. Honouring the truth, reconciling for the future - summary of the final report of the truth and reconciliation commission of Canada. 2015 http://www.trc. ca/websites/trcinstitution/File/2015/Findings/Exec_Summary_2015 05_31_web_o.pdf (accessed 12 Jun 2017).

51. Barbee L, Kobetz E, Menard J, et al. Assessing the acceptability of self-sampling for HPV among haitian immigrant women: CBPR in action. Cancer Causes Control 2010;21:421-31.

52. Berner A, Hassel SB, Tebeu PM, et al. Human papillomavirus selfsampling in Cameroon: women's uncertainties over the reliability of the method are barriers to acceptance. J Low Genit Tract Dis 2013;17:235-41.

53. Dzuba IG, Díaz EY, Allen B, et al. The acceptability of selfcollected samples for HPV testing vs. the pap test as alternatives in cervical cancer screening. J Womens Health Gend Based Med 2002;11:265-75.

54. Litton AG, Castle PE, Partridge EE, et al. Cervical cancer screening preferences among African American women in the Mississippi Delta. $J$ Health Care Poor Underserved 2013;24:46-55.

55. Waller J, McCaffery K, Forrest S, et al. Acceptability of unsupervised HPV self-sampling using written instructions. J Med Screen 2006;13:208-13.

56. Cadman L, Wilkes S, Mansour D, et al. A randomized controlled trial in non-responders from Newcastle upon Tyne invited to return a selfsample for human papillomavirus testing versus repeat invitation for cervical screening. J Med Screen 2015;22:28-37.

57. Penaranda E, Molokwu J, Hernandez I, et al. Attitudes toward self-sampling for cervical cancer screening among primary care attendees living on the US-Mexico border. South Med $J$ 2014;107:426-32.

58. Raymond NC, Osman W, O'Brien JM, et al. Culturally informed views on cancer screening: a qualitative research study of the differences between older and younger somali immigrant women. BMC Public Health 2014;14:1188.

59. Zehbe I, Wakewich P, Wood B, et al. Engaging Canadian first nations women in cervical screening through education. Int $J$ Publ Health Promotion Education 2016;75:331-42.

60. Crofts V, Flahault E, Tebeu PM, et al. Education efforts may contribute to wider acceptance of human papillomavirus selfsampling. Int J Womens Health 2015;7:149-54.

61. Wakewich $\mathrm{P}$, Wood B, Davey $\mathrm{C}$, et al. Colonial legacy and the experience of first nations women in cervical cancer screening: a Canadian multi-community study. Crit Public Health 2016;26:368-80. 